\title{
Studying the Impact of Indian Urban Parenting on Emotion Regulation in female children and adolescents during CoVID-19: A Cultural Analysis
}

Ritwik Khurana ( $\nabla$ khurana.ritwik@gmail.com)

IILM Institute for Higher Education https://orcid.org/0000-0002-7971-7295

\section{Saakshi Singla}

IILM Institute for Higher Education

\section{Research Article}

Keywords: Child \& Adolescents, Parenting Styles, Emotions, Indian Family, Diversity.

Posted Date: May 21st, 2021

DOI: https://doi.org/10.21203/rs.3.rs-484500/v1

License: @ (i) This work is licensed under a Creative Commons Attribution 4.0 International License. Read Full License 


\section{Abstract}

We focus on Indian parenting and its impact on emotion regulation in female first born offspring residing in an Urban complex. The case report relies on a case report analysis between two groups, A and B. Group A comprises two families, and their young children, while Group B consisted of two families with adolescents. Extensive qualitative analysis has been conducted to understand the ground reality of Indian parenting practices and the emotional mechanisms present in children and adolescents during the COVID-19 crisis. Multiple baseline design was followed and the measures employed were the Parenting style questionnaire (Robinson Et. Al., 1995) and Difficulties in emotion regulation scale (Gratz \& Roemer, 2004), where the parents, ages between 30 and 55 years, were supposed to fill the PSQ and their children (Ages between 4 and 18 years) completed the DERS through an online test form. This was followed by a semi-structured interview to complete the analysis and get a better idea about the family dynamic. We achieved two goals; (1) It was found that the Indian family functions in a complicated manner and studying it required creating novel constructs to accommodate the cultural diversity. Conveying a real lack of present work done by Indian researchers to effectively come to any conclusion, (2) It was discovered that young children are bound to face novel challenges, caused by a new style of parenting which comprises of mixed parenting style with a focus towards maintaining cultural values and social norms. Adolescent females, unfortunately do face an authoritarian father, on an above average basis, but this is changing as the parents from Group A were observed employing mixed parenting. Which has proved our assumptions correct.

\section{Highlights}

- Targeted young female children reported an average level of difficulty in emotion regulation skills as compared to their adolescent counterparts.

- Parents of adolescents from middle class families are prone to employ a more "black \& white" approach for parenting in India, being either authoritarian or permissive.

- Improper understanding of socio-emotional competencies in parents, can be detrimental in the emotional development of children and adolescents in a multicultural environment.

- Promotion of family education programs and emotion sensitivity training can enhance the quality of life for many families.

\section{Introduction}

Parenting is a worldwide phenomenon, whose existence is essential and necessary for the development of a human being from birth. Still its application is one of the toughest ordeals, which young couples often face after the birth of their offspring. A popular quote, "Parenting is a full-time job" rings true in most cases. It is well understood that as children grow up the responsibilities of the parents keep decreasing, as the child becomes independent and capable of becoming a functional member of society.

And as the child grows, with the support and encouragement of their parents, they contribute their share to the society, just like their parents did before. Which makes the family an integral part of the society, just like a microsystem (Bronfenbrenner, 1977). This unit can be considered like a cell, which then in its collective existence in millions constitute an organism. But each organism contains different kinds of cells, so can we consider this family-cell system to be different for differing regions in the world? It is pertinent to consider the impact that culture has on the family unit. In this thesis, our focus will be on the south-east Asian family unit, specifically from India.

As a collectivistic culture, the Indian family relies on the co-operation and interdependence among the members, and usually treats this unit as being more answerable and responsible for the caregiving, as compared to the individualistic culture present in the west (Chadda and Deb, 2013). But, in the past 50 years slowly this collectivistic system is collapsing in the urban areas, which has given rise to nuclear families in cities, albeit with the same collectivistic values (Sondhi, 
2017). Parenting, as an important duty of this family unit, when evaluated separately from its cultural context is not that different. Parenting often requires a couple to display a multitude of qualities for rearing a child, qualities like - patience, understanding, unconditional love and support (Khurana, 2021). Even though one is highly likely to find stark differences between the family units present in the eastern and western cultures, historically there is ample evidence for joint, nuclear, single parent, dual earner and adoptive families present in India (D'Cruz and Bharat, 2001). So, can we say that despite cultural differences, parenting styles practiced among western and eastern families are largely similar? It is definitely so. Even though one cannot ignore the contextual limitations of being born in a specific culture, it is important to evaluate the impact of parenting, by relying on the standardised scales which measure a parent's general tendency to react towards their child. Bronfenbrenner's model stipulated that the minor aspects of the system have the same amount of power to influence and stimulate change as the much bigger counterparts, continuing with that thought, what about the emotional behaviour of children and adolescents as a reaction to parenting styles? It is important to evaluate them too.

\section{Emotion Regulation}

Before discussing the history of parenting styles, it is necessary to develop an understanding of basic emotion regulation in children, formed by parental interaction in early childhood. The emotional climate of the family is reflected in family and parent-child relationships. A secure parent and child relationship helps children feel supported and emotionally safe, which is a prerequisite for effective emotional regulation (Morris Et. Al., 2017). Moreover, emotional climates in which children feel closeness and warmth help them express their emotions more comfortably (Houltberg Et. Al., 2012).

Which signifies the importance of proper emotion regulation in children, which often results from healthy early interactions with parents and family members. The tripartite model posited by Morris Et. Al. (2007), succinctly explains the effect of family influence on the emotion regulation of children, which consists of (1) Observational learning, modelling and social referencing (2) Parenting practices related to emotions (3) The emotional climate of the family from parenting styles, attachment relationships, family expressiveness and marital relationships, are some of the characteristic features of this model. Morris's investigation into the family contexts in child emotion regulation tries to review and conclude on the variety of factors which affect a child's ability to control and regulate their emotions. Although important, emotion regulation cannot be discussed in a vacuum, it is pertinent to consider the governing mechanisms of emotions. Just like the measure of cognitive intelligence in psychometric testing is IQ, similarly emotions are measured by a concept called emotional intelligence or EQ.

\section{Emotional Intelligence}

As a concept, Emotional intelligence was introduced by Goleman in 1995 with his bestselling book "Emotional Intelligence". Goleman introduced five components of EQ, which are necessary for a an emotionally intelligent person to inculcate, (1) Self Awareness* (2) Self Regulation* (3) Internal Motivation (4) Empathy (5) Social Skills. Self awareness and self-regulation being the most important characteristics of an emotionally intelligent person.

A person's emotional intelligence plays an important role in their ability to regulate their emotions in real time. As children and adolescent's IQ can be measured, similarly their EQ is measured as it develops over time through the course of development. "Mayer-Salovey-Caruso Emotional Intelligence test" or MSCEIT is one of the foremost tests developed by Mayer, Salovey and Caruso in 2002. They introduced a sixteen-step developmental model from childhood to adulthood, which comprised of four branches; (1) Being able to be receptive of emotions of oneself and others accurately (2) Using

emotions to facilitate thinking (3) Understanding emotions, emotional language and signals conveyed by emotions (4) Ability to manage emotions to achieve specific goals (Mayer Et. Al., 2008).

\section{Parenting Styles}


A developmental and clinical psychologist, Diana Baumrind pioneered in constructing a model, which described three types of parents; (1) Authoritative (2) Authoritarian (3) Permissive. Her conceptualisation of parenting styles has been especially helpful for all developmental psychologists. The authoritative parent is a person who gives an open ear to their child, is warm and provides a tender approach to understanding the needs and demands of their offspring. Also expecting their child to live up to certain expectations.

On the other hand, an authoritarian parent would be the one, who has the tendency to employ corporal punishments on their children, are highly demanding and not necessarily abusive. A permissive parent is characterised as a person who has very low demands from the child and is highly responsive to the child's needs and wants. This type of parenting style often produces "spoilt" children. Baumrind made a clear distinction between authoritative and authoritarian styles of parenting, as common folks made mistakes between the two. It is the enactment of the role of an inhibiting authority rather than a rational authority, which characterises a person's interpersonal relations (Baumrind, 1966).

While it is important to consider that Baumrind's theory is still used by researchers while conducting psychological research in recent times. Maccoby and Martin (1983) further included a fourth style of parenting i.e., "Neglectful" or Uninvolved parenting. This kind of parent is characterised as cold, unresponsive and indifferent to the needs of the child. In this thesis we will focus on the three main styles of parenting in the Indian context.

\section{The Indian Parent}

The western perspective, albeit very scientific and applicable, misses out on a global perspective of its generalisability. Although not its own fault, it forces the researcher's native to south-east Asian countries to produce validation studies, which more or less employs a western perspective on its psychometric testing. We will be employing the three common parenting styles as a measure, but it is important to gain an insight on how Indian parents behave. Indian parents, often typified as being "Authoritarian" in the popular culture are considered to be controlling and worried about their child's future, often as a way to defend their communal image in society (Khurana, 2021). Still traditional Indian parenting has certainly evolved from a more patriarchal model (D'Cruz and Bharat, 2001) towards a more authoritative style with maternal independence in contemporary society (Sondhi, 2017).

\section{Objectives of the Study}

Our study aims to analyse and evaluate the impact of parenting styles on emotion regulation in young girls \& adolescents residing in an urban area of Delhi, India. It specifically wants to study the degree of style employed by Indian parents, following the Baumrind model, and the level of emotion regulation in children and adolescents. Which will be done by reviewing two separate case studies, consisting of two groups of two families in each study.

1. We will try to find a deeper connection between a parent's ability to rear a female child/adolescent and the latter's regulation of their emotions.

2. To evaluate the information obtained from the semi-structured interviews conducted on the participants and assimilate it with the study.

3. To evaluate the implications, present in parenting children during the pandemic and make effective strategies to further improve the parent-child relationship for future well-being.

\section{Previous Studies}

As a deeply rooted collectivistic society, India often relies on its family values and expects the family to be there for each other during difficult times. Keeping this in mind Chadda and Deb (2013) state that India can really benefit from psychotherapy, which is geared towards a family-centric approach, i.e., family-oriented psychotherapy. Further stating that attitudinal differences between eastern collectivistic culture and western individualistic culture can play a role in 
hampering adolescent treatment in family-oriented psychotherapy. Unlike the western culture, adolescents needing help may face personal problems in approaching a mental health professional, as having personal opinions and experiences which do not match with the conventional mores of the society, is often looked down upon in India. Which is exacerbated by the belief that outside help signifies a failure of the family to take care of its members. Family oriented psychotherapy, although can provide great relief in the parent-child/adolescent relationship, is not able to meet the demands of a country, with aforementioned limitations.

A study feigning comparison between the Indonesian (Eastern) and Australian (Western) cultural values pertaining to parenting styles, emotion regulation in children and behaviour problems stated that higher level of authoritative parenting was associated with a better child emotion regulation and lower levels of behavior problems. And lower level of emotion regulation and high levels of behavior problems was associated with authoritarian style of parenting (Haslam Et. Al, 2020).

Although it was noticed that a greater emphasis placed on tradition produced significantly better outcomes in association with authoritative parenting in both the countries, here tradition being the individualistic and collectivistic norms of society. An Iranian research found significant correlation between Borderline personality disorder and authoritarian parenting, moreover it discovered emotion regulation strategies of reappraisal and suppression to be significant predictors of BPD and its components (Etemadi Et. Al., 2020). This study on Iranian school students and their parent has been significantly more scientific than other researches, in the sparse literature available to us on parenting and emotion regulation. A child protective services-based study in US studied the level of emotion regulation among children in foster care and those with their birth parents. These two randomized control trials concluded that children whose birth parents received parenting interventions showed lower anger dysregulation as compared to those who didn't. Children in foster care displayed lower anger dysregulation regardless of their caregivers receiving any intervention, and were high in adaptive regulation (Labella Et. Al., 2020).

One of the few researches conducted on emotion regulation in children with anxiety disorders, Suveg and Zeman (2004) conducted a study on 8-12-year-old children with anxiety disorders and the children who did not have it. The study discovered that children with $A D$ reported more inhibition of worry than children with no AD. The children diagnosed with $A D$ had difficulties in managing worried, sad and angry experiences, particularly due to feeling those same emotions very intensely. A majority of research done on emotion regulation focuses on the adult population, to tackle this dilemma, Braet Et. Al. conducted a study which aimed to find out if the emotion regulation strategies existing in adults, also existed in children. Proving that studies conducted on children and adolescents can be useful for transdiagnostic interventions, as children are capable of using cognitive strategies that require control over emotional reactions. Which further proved this particular assumption wrong about children not being able to employ proper strategies.

In a special issue, Jones and Hussong (2018) highlighted the increasing levels of diversity in United states and the increasing need for cultural competence in the parent-child relationship. Population diversity, according to them has caused a need to become aware of changing domestic demography and international context in family values and relationships. A six-year longitudinal bidirectional study based on the parenting and youth outcomes was studied, beginning with children aged 8 years, with family reports evaluated from nine countries (Italy, Jordan, Kenya, Philippines, Sweden, Thailand, United States, Colombia and China). It was found that predicting parental warmth from child externalizing behavior were similar across all groups (Lansford Et. Al., 2018). Which to a certain extent stipulated that traditional theories of parenting (Baumrind and others) are universally linked with parenting and youth outcomes. Jones, Hussong and Jensen (2018) introduced three tasks of diversity socialization, which predominated their special issues, that are necessary for a parent to inculcate in their offspring. The first is to encourage and uplift their place and value in a multicultural world, the second one emphasizes the parent to help an adolescent in increasing the values they place on others to reduce their fear of differences. The third task is for parents to be able to adequately prepare their offspring to deal with a world which might reject them on the basis of existing differences. These values are extremely pertinent for urban parenting, as a sign of a world which is changing and accepting diverse ideas and opinions.

Page 5/14 
The minority communities living as Non-resident Indians in western countries also give an insight to the influence of cultural mores which exist among Indians living abroad. A study comparing the parenting attitudes of Asian Indian mothers living in the US and those living in India, found that Asian Indian mothers favored the use of corporal punishment more than their counterparts residing in United States (Jambunathan and Counselman, 2010). Which exactly proves the partial cultural assimilation in parenting styles. A similar study conducted by Sapru (2006) examined sets of Indian parents and their adolescents residing in Geneva and New Delhi, seeking to understand the ancestral and cultural meanings in immigrant Indian parenting. The parents residing in Geneva placed more importance on having an Indian cultural setting at home and adolescents in Geneva were found to be less dependent on their parents than the ones from Delhi. Which ultimately meant that the adolescents constructed their identity in relation to others, by following their parent's cultural identity and their place of origin. While we have discussed researches focusing on mixed gender, considering the goals of this study, Sanchis Et. Al (2020) analyzed the effects of gender in emotion regulation in children. Girls were prone to having more emotion regulation strategies when they were younger as compared to boys, and lower scores than boys when they were older. This signifies the need to empirically understand gender differences while evaluating emotion regulation among children and adolescents.

\section{The Current Study}

Very sparse literature has been available to duly understand the importance of parenting and emotion regulation in children in the Indian context. Furthermore, only limited research has been done to understand the emotional experience of children and their ability to cope with difficult emotions globally. While we rely on two case studies involving two sets of parents, and their female child/adolescent in two separate studies, it aims to collectively understand the impact. It is also important to consider that, our work has been done during the COVID-19 pandemic and may also show results pertaining to that specific event. Delhi being a heavily populated area had been forced under an extensive lockdown and all the services were limited to bare essentials. With common people already under great duress due to loss of jobs, financial problems and loss of mobility. Great sensitivity had been maintained while working with all persons.

\section{The feminine perspective}

India as a patriarchal society has largely ignored the condition of the female members of its society. It is a stark reality that the country still needs to realise the role of its women in becoming a backbone of its family and cultural mores. Gender equal parenting is a concept which is still being understood by the urban members of the country, as the persons living in rural areas or second tier cities are still entrapped in the patriarchal values.

We aim to fulfil this mission by contributing to the sparse literature present in the country for how parenting affects female public health by creating a case report, that can be used to create strategies to improve future work.

\section{Methodology}

\section{Participants}

All participants $(N=12)$ were recruited randomly through a pool of prospective families, who applied to take part in the parenting research (See Table 1 Refer to the appendix.). The research was advertised on professional websites and prospective participants; consisting of the mother, father and the first-born female offspring from the ages 4 to 18 . The study advertising materials can be found in the supplementary materials. To be eligible for the study, the parents needed to belong to a middle-class socio-economic condition and residing in an urban complex in New Delhi. The participants received Rs. 500 online transfer of money for their time. A total of four families were finalised for the final study, who were divided in groups A \& B, with group A consisting of two sets of parents (Male and female) and their daughter's (Ages= 6 and 5.5 years old) respectively. 
And group B consisting of two sets of parents (Male and female) and their daughter's (Ages= 16 and 17) respectively. Careful care was taken to conduct this study, as it was not possible to be physically present to collect data (COVID-19), the testing and semi-structured interviews were conducted with the help of survey forms and Zoom calls respectively.

\section{Measures}

The study, following the multiple baseline design, has been conducted on each family on separate occasions, constituting two measures, which are the Parenting style questionnaire and Difficulties in emotion regulation scale, the statistical analyses have been done with the help of the open-access software called JASP. The parenting style questionnaire (Robinson Et. Al, 1995), consisting of 30 items, divided between the sub-scales Authoritative, Authoritarian and Permissive (Baumrind, 1966). The test has been conducted on parents in group A \& B and the item questions relating to specific types of parenting has not been disclosed to the participants. Participants were assessed regarding the degrees of parenting styles they employed while parenting, through rating the items belonging to each parenting sub-scales (hidden) on a 6point Likert scale $(1=$ Never, $6=$ Always). The scale displays very good Internal consistency for; Authoritative $(a=0.91)$, Authoritarian $(\alpha=0.86)$ and Permissive $(\alpha=0.75)$ (Robinson Et. Al, 1995).

The Difficulties in emotion regulation scale (Gratz \& Roemer, 2004), consists of 30 items, which have been divided among six sub-scales; (1) Nonacceptance of emotional responses (2) Difficulty engaging in goal-directed behavior (3) Impulse control difficulties (4) Lack of emotional awareness (5) Limited access to emotion regulation strategies (6) Lack of emotional clarity. This test was conducted on the first-born female offspring of both groups A \& B. Group A consisting of participants in the ages 5.5 and 6 years of age, were helped by their parents to complete the test form. The participants of Group B (Ages 16 \& 17) completed the test form without any external help. This test employed items which measured the level of emotion regulation in the participants, who rated the items belonging to each sub-scale on a 5-point Likert scale (1= Almost Never, $5=$ Almost Always).

The scale displays good internal consistency, particularly when the Awareness subscale is excluded, which indicates that awareness might be a different construct (Hallion Et. Al., 2018). The means and standard deviations from sample for the construct are; Total $M=89.33, S D=22.64$ - Non-acceptance $M=14.67, S D=5.92$ - Goals $M=15.42, S D=4.215$-Impulse $M=12.58, S D=4.97$ - Awareness $M=15.55, S D=4.92-$ Strategies $M=19.67, S D=7.31-$ Clarity $M=12.01, S D=4.04$.

\section{Other measures}

The parents and the children/adolescents belonging to Groups A \& B were separately interviewed for 15 minutes individually, the children from group A being accompanied by their parents. The interview was simple and entailed a short feedback of what they learned through the test, and their personal opinions regarding the effects of parenting and how a person should take charge of their emotions. The interview was simple and concluded the testing in a positive manner.

\section{Procedure}

After joining the Online video call, the parents and the children/adolescents were greeted by the experimenter (The testing was conducted at separate occasions for each of the four families). They were asked to put their smartphones on the silent mode and to sit somewhere where they would not be disturbed. The participants agreed, and once they were ready, the were instructed to click the test form link and asked to give consent by checking a box, which detailed information regarding the study and the activities involved.

After providing informed consent, the mothers were instructed to fill the test form, after finishing the father was supposed to finish the test form and pass it on to the child/adolescent to complete it. To mask the true purpose of the study, the participants were oblivious to the nature of the tests and its goals. Furthermore, the form was constructed in a way where the participants had to complete a section and pass it to the next person to finish it. Following this pattern, the young children from group A were able to fill the test form with the help of their parents. 


\section{Results}

Figure 1. Mothers and fathers from Group A (M1, F1, M2, F2) and Group B (M3, F3, M4, F4). Fathers (F3, F4), as compared to the mothers $(M 3, M 4)$, are more likely to have a tendency to be authoritarian towards their female offspring $(A=2.69,4$, $B=2.69,5.69)$. Fathers from both the groups, have showed increasing patterns of authoritarian style of parenting, while those from Group B having a lower degree of permissive behaviour towards their adolescents $(B=1.5,1)$. But have a greater tendency to be permissive when their child is much younger $(A=2.5,4.7 .5)$.

Mothers on the other hand have a more balanced approach to parenting, having almost similar degree of parenting styles employed across the three styles, have a slightly less authoritarian behaviour with female adolescents as compared to the father $(B=3.3,4.23)$. Table 2. also shows more permissive attitudes towards the younger child, Group $A$, than those with Group B.

Table 2. (Refer to the appendix) Tells the impact of moderate and high authoritarian parenting, by the mother and father, parents of adolescent 4; having a high score on the test. Which means this adolescent has a tougher time regulating their emotions, as compared to the Group B adolescent 3, whose parents have employed a moderate level of authoritative and authoritarian parenting styles. Particularly, this adolescent has difficulties in accessing emotion regulation strategies, proving the existence of certain emotional and behaviour difficulties (Impulse control=29).

Young children from Group A, even though through the help of their parents, have reported an average level of emotional difficulty, keeping in mind the parenting behaviour of their parents. Interestingly the two families in Group A have displayed a mixed parenting style, by using the three on average, which indicates the tendency of parents to be equally uninvolved while rearing young children (ages 5-8) in urban India.

\section{Interview}

When asked about their opinion, parents from Group B were more upfront about their ability to understand their children and be receptive. While those from Group A were reticent about their abilities and elaborated on the strengths and weaknesses of their child. One of them said "I believe parenting is an essential job of a household, and my bright child has proven to be the best example of it" (Translated from Hindi) *. The parents were then asked to give feedback on their experience of giving the test and if they learned something from it; the response was positive and the parents were happy they were able to learn something about themselves.

The mother of Adolescent 4 (Group B) commented that she felt guilty of not being conscious while parenting her child, and was thankful that this test made her become more conscious of how parenting works. Interestingly the fathers were silent and were visibly puzzled about the need for studying parenting. One of the fathers stated "Parenting is such a common phenomenon, why study it?" *, an effort was made to clear the doubts and misconceptions of that father duly. The children in Group A were smiling from ear to ear, one girl said "Now finally someone has put a check on my mama" *, the other girl noticed how emotions were being discussed and said "I get bored when my papa does not give me phone when I'm free" *. Whereas the adolescents in Group B were significantly much more detailed with their ideas, given, them being much older. One said "I feel my capacity to express my emotions is often hindered by how my mom and dad are willing to listen to me, I often feel left out of conversations", while the other girl stated "I'm unable to express as I feel I will be misunderstood by my family members, I always try to convey my concerns in a very stoic manner" *.

\section{Discussion}

The evaluation proves our assumption for existing ideas of parenting discussed before. Observing the degree of parenting employed by the fathers, the study showed them being too permissive when the girl child is young, and becoming authoritarian when they enter adolescence (Group B adolescents, Table 3). Which begs the questions, why is there no 
middle ground present? Cultural notions of masculinity often characterise how families facilitate the upbringing of children in India (Khurana, 2021) as the social mores of the society prohibit the proper expression of emotions among the male populations, who comprise a majority against the female population of the country (StatisticTimes, 2021). This information along with our own observation, strongly indicate a lack of proper emotional awareness and understanding amongst the male adult population itself.

Now it might seem that we are emphasising on a specific point repeatedly, but this is one of the strongest highlights of the case report. Moreover, the Group B adolescent 4, faced the most difficulties in accessing emotion regulatory coping strategies and had problems in accepting their emotions. During the interview the same participant mentioned her inability to feel that their family truly understands them and consequently they just convey their thoughts without considering their emotions, and not expressing them. An important change which was observed between the two groups, has been the evolving degrees of parenting in the past few decades. Parents have made an effort to balance the time they spend with their children, keeping in mind the changing career and household responsibilities, with an increase in divided attention, it is natural for them to ignore their child or lose motivation to involve themselves with their children for a longer period of time. Although globally this detachment is not a new phenomenon, this pattern of behaviour is a new addition to an everincreasing change in traits of a diverse urban population. Which has resulted in an average level of problems in emotion regulation faced by young girls, which proves Sanchis Et Al..'s (2021) conclusion regarding young girls having less emotion regulation difficulties as compared to older girls wrong, as cultural contexts also need to be understood. The other styles (Authoritative, authoritarian) had an equal degree of employment here.

In the interview the young girls quickly pointed out the accountability patterns of their parent's existing behaviour, when one girl mentioned her mother being "Checked" and the other talking about not being provided a mobile phone by her dad when she is "free and gets bored". Which realistically does not account much, but certainly proves the child preferring the company of an electronic gadget over her father, which usually forms as a result of unresponsive parenting. The case report consists of all the mothers being housewife's and only the father being an employed professional, who is the sole breadwinner of the family. After considering this aspect, the results do not reflect this reality, most likely due to the evolving urban social mores of the society. This division of family responsibility is a reality in India for a long time now.

\section{Limitations of the study}

No study is capable of producing perfect results, and our case report also entailed certain limitations, which I had to work with. The first limitation would be the effect of the pandemic, COVID-19, on the parenting styles and emotion regulation strategies being studied. It has been proved that the isolation caused by the pandemic has exacerbated the levels of emotional difficulties and anxiety among homebound people (Lee Et. Al., 2020; Montemurro, 2020), which is an unfortunate reality and an extraneous variable here.

The second limitation was the Group A's assisted filling of test form for the young children. During the online video call, it was made sure that the test was conducted properly, but there was no way to personally oversee the proper conduction as everything was online. The third limitation is the online mode, which has created immense problems in conducting data collection and extensive field research, as the pandemic took an ugly shape in Delhi, it became apparent that no physical studies could be followed through in the present scenario.

\section{Strategies for future}

A few strategies need to be considered to influence change in parenting, emotional well-being and gender sensitivity amongst families residing in urban complexes in India. Firstly, Promotion of family education programs, which emphasise the acceptance of diverse competencies and difficult emotions which need to be expressed among members of a family. The program need not be an intervention, but a short-term skill development which can be applied in daily life by the participants after completion. It can also include dealing with gender biases by clearing erroneous beliefs impregnated 
during childhood. The second would be Emotional sensitivity training, which emphasis the acceptance of one's own emotions and those of others. Which will contribute significantly to children and adult's Emotional Quotient. This can be done by inviting the parents to sit in a circle, and asked to share their emotions frankly, without fear of judgement. And the third strategy will need to be De-sensitizing seeking help from a mental health professional, as a nation and community, India needs to have this policy be implemented by authorities present at state and central jurisprudence.

\section{Conclusion}

The concept of parenting, while well respected in India, is misunderstood in its impact and the contextual circumstances it has evolved over time. The aim of this paper was to study a small sample, where there could be an accurate evaluation of parenting and its emotional effects on the middle-class girl child \& adolescents residing in urban India. While cultural contexts change in specific regions in India, this qualitative case report has been conducted to throw light in the areas of parental, emotional and gender based scientific psychological research for future academic development. It aims to solidify a benchmark, to highlight the need of intensive research work which needs to take place in India to bridge this gap, it is my wish that this work stimulates further research in the future.

The proposed strategies can only be effective if the Indian Government in the Central and State levels can promote these programs to take place in Private institutions, more so than public, because the general conception of an Indian person regarding the implementation of "government" programs is bad. At budget friendly cost, persons can come and attend the educative and skill development seminars/classes which will definitely bring positive change in the present social mores of the urban society. With consistency, one will definitely notice great strides in improvement in family dynamics of the same persons.

\section{Declarations}

Ethical Approval: All procedures performed in this study involving human participants were in accordance with the ethical standards of the institutional committee and with the 1964 Helsinki declaration and its later amendments or comparable ethical standards. This study was performed in line with the principles of the Declaration of Helsinki. Approval was granted by the Committee on the Use of Human Subjects of IILM University. (Date: September 23, 2020)

Acknowledgements: All thanks go to my professors Drs. Megha Pushkarna, Megha Kochhar \& my guide and co-author Ms. Saakshi Singla in inspiring me and pushing my abilities to conduct empirical work. This article is based on a Senior Honors Thesis project in the Department of Psychology at IILM University, conducted by the first author and co-supervised by the second author.

Author Contributions: RK developed the study concept. Both the authors have worked towards the study design. Data collection and analysis were conducted by RK under the supervision of SK. RK drafted the paper and all authors approved the final version of the manuscript for submission.

Funding: There has been no funding for this study.

Conflict of Interest: Ritwik Khurana and Saakshi Singla declare that they have no conflict of interest.

\section{References}

Baumrind, D. (1966). Effects of Authoritative Parental Control on Child Behavior. Child Development, 37(4), 887-907. doi: $10.2307 / 1126611$ 
Braet, C., Theuwis, L., Durme, K.V., Vandewalle, J., Vandevivere, E., Wante, L., Moens, E., Verbeken, S., Goossens, L. (2014). Emotion Regulation in Children with Emotional Problems. Cognitive Therapy and Research. 38. 493-504. 10.1007/s10608014-9616-x.

Bronfenbrenner, U. (1977). Toward an experimental ecology of human development. American psychologist, $32(7), 513$.

Chadda, R. K., \& Deb, K. S. (2013). Indian family systems, collectivistic society and psychotherapy. Indian journal of psychiatry, 55(Suppl 2), S299-S309. https://doi.org/10.4103/0019-5545.105555

D'cruz, P., \& Bharat, S. (2001). Beyond joint and nuclear: The Indian family revisited. Journal of Comparative Family Studies, 32(2), 167-194.

Etemadi, M., Aghebati, A., Ayatmehr, F., \& Ashoori, A. (2020). Predicting Borderline Personality Traits in Adolescents Based on Parenting Styles and Emotion Regulation Strategies. Journal of Practice in Clinical Psychology, 8(2), 133-142. https://doi.org/10.32598/jpcp.8.2.656.1

Goleman, D. (1995). Emotional intelligence: Why it can matter more than IQ. New York: Bantam Books. ISBN-10 9789382563808, ISBN-13 978-9382563808

Gratz, K., Roemer, L. (2004). Multidimensional Assessment of Emotion Regulation and Dysregulation: Development, Factor Structure, and Initial Validation of the Difficulties in Emotion Regulation Scale. Journal of Psychopathology and Behavioral Assessment. 26. 41-54. 10.1007/s10862-008-9102-4. DOI: 10.1007/s10862-008-9102-4

Hallion, L.S., Steinman Shari A., Tolin, D.F., Diefenbach, G.J. (2018) Psychometric Properties of the Difficulties in Emotion Regulation Scale (DERS) and Its Short Forms in Adults With Emotional Disorders. Frontiers in Psychology. Vol.9 (539) DOI=10.3389/fpsyg.2018.00539

Haslam, D., Poniman, C., Filus, A., Sumargi, A., Boediman, L. (2020) Parenting Style, Child Emotion Regulation and Behavioral Problems: The Moderating Role of Cultural Values in Australia and Indonesia. Marriage \& Family Review. 56:4, 320342, DOI: 10.1080/01494929.2020.1712573

Houltberg, B., Henry, C., Morris, A. (2012). Family Interactions, Exposure to Violence, and Emotion Regulation: Perceptions of Children and Early Adolescents at Risk. Family Relations. 61. 10.1111/j.1741-3729.2011.00699.x.

Hussong AM, Jones DJ. (2018) Parenting Adolescents in an Increasingly Diverse World: Defining, Refining, and Extending Theory and Research. Journal of Research on Adolescence: The Official Journal of the Society for Research on Adolescence. 28(3):568-570. DOI: 10.1111/jora.12398.

Hussong, A., Jones, D. J., \& Jensen, M. (2018). Synthesizing a Special Issue on Parenting Adolescents in an Increasingly Diverse World. Journal of research on adolescence: the official journal of the Society for Research on Adolescence, 28(3), 665-673. https://doi.org/10.1111/jora.12397

J.D., Salovey, P., Caruso, D.R. (2008). Emotional Intelligence: New Ability or Eclectic Traits? American Psychologist. Vol. 63, No. 6, pages 503 - 517. 10.1037/0003-066X.63.6.503

Jambunathan, S., Counselman, K. (2002) Parenting Attitudes of Asian Indian Mothers Living in the United States and in India, Early Child Development and Care, 172:6, 657-662, DOI: 10.1080/03004430215102

Khurana, R. (2021, Jan. 31). Why are (Indian) men supposed to hide their emotions? Ritwik Khurana. https://ritwikkhurana.wordpress.com/2021/01/31/posts/ 
Khurana, R. (2021, March 21). A cross-cultural perspective on Child rearing. Ritwik Khurana.

https://ritwikkhurana.wordpress.com/2021/03/15/a-cross-cultural-perspective-on-child-rearing/

Labella, M.H., Lind, T., Sellers, T. et al. Emotion Regulation among Children in Foster Care Versus Birth Parent Care: Differential Effects of an Early Home-Visiting Intervention. J Abnorm Child Psychol 48, 995-1006 (2020). https://doi.org/10.1007/s10802-020-00653-4

Lansford, J. E., Rothenberg, W. A., Jensen, T. M., Lippold, M. A., Bacchini, D., Bornstein, M. H., Chang, L., Deater-Deckard, K., Di Giunta, L., Dodge, K. A., Malone, P. S., Oburu, P., Pastorelli, C., Skinner, A. T., Sorbring, E., Steinberg, L., Tapanya, S., Uribe Tirado, L. M., Alampay, L. P., \& Al-Hassan, S. M. (2018). Bidirectional Relations Between Parenting and Behavior Problems From Age 8 to 13 in Nine Countries. Journal of research on adolescence: the official journal of the Society for Research on Adolescence, 28(3), 571-590. https://doi.org/10.1111/jora.12381

Lee, S.A., Mathis, A.A., Jobe, M.C., Pappalardo, E.A. (2020) Clinically significant fear and anxiety of COVID-19: A psychometric examination of the Coronavirus Anxiety Scale. Psychiatry Research. Vol. 290, 113112, ISSN 0165-1781 https://doi.org/10.1016/j.psychres.2020.113112.

Maccoby, E. E., \& Martin, J. A. (1983). Socialization in the context of the family: Parent child interaction. In P. H. Müssen (Series Ed.) \& E. M. Hetherington (Vol. Ed.), Handbook of child psychology: Vol. 4. Socialization, personality, and social development (4th ed.). New York: Wiley.

Mayer, J. D. (2002). MSCEIT: Mayer-Salovey-Caruso emotional intelligence test. Toronto, Canada: Multi-Health Systems. Montemurro N. (2020). The emotional impact of COVID-19: From medical staff to common people. Brain, behavior, and immunity, 87, 23-24. https://doi.org/10.1016/j.bbi.2020.03.032

Morris, A. S., Criss, M. M., Silk, J. S., \& Houltberg, B. J. (2017). The Impact of Parenting on Emotion Regulation During Childhood and Adolescence. Child Development Perspectives. DOI: 10.1111/cdep.12238

Morris, A. S., Silk, J. S., Steinberg, L., Myers, S. S., \& Robinson, L. R. (2007). The Role of the Family Context in the Development of Emotion Regulation. Social development (Oxford, England), 16(2), 361-388.

https://doi.org/10.1111/j.1467-9507.2007.00389.x

Robinson, C., Mandleco, B., Roper, S., Hart, C. (1995). The Parenting Styles and Dimensions Questionnaire (PSDQ). Handbook of Family Measurement Techniques. 3. 319-321.

Sanchis-Sanchis, A., Grau, M. D., Moliner, A. R., \& Morales-Murillo, C. P. (2020). Effects of Age and Gender in Emotion Regulation of Children and Adolescents. Frontiers in psychology, 11, 946. https://doi.org/10.3389/fpsyg.2020.00946

Sapru, S. (2006). Parenting and Adolescent Identity: A Study of Indian Families in New Delhi and Geneva. Journal of Adolescent Research, 21(5), 484-513. https://doi.org/10.1177/0743558406291766

Sondhi, R. (2017). Parenting adolescents in India: A cultural perspective. In Child and Adolescent Mental Health (pp. 91102). doi: $10.5772 / 66451$

StatisticsTimes (n.d.) Gender Ratio in India. https://statisticstimes.com/demographics/country/india-sexratio.php\#: :text=There\%20are\%20717\%2C100\%2C970\%20or\%20717.10,males\%20population\%20of\%2054.20\%20million.

Suveg, C., \& Zeman, J. (2004). Emotion regulation in children with anxiety disorders. Journal of clinical child and adolescent psychology, 33(4), 750-759. 


\section{Tables}

Table 1. Socio-demographic Details of the participants who volunteered for the study.

$\begin{array}{llcl} & \text { Occupation } & \text { Age (In years) } & \text { Gender } \\ \text { Group A } & & & \\ \text { Father 1 } & \text { Businessman } & 37 & \text { Male } \\ \text { Mother 1 } & \text { Homemaker } & 35 & \text { Female } \\ \text { Child 1 } & \text { First Grade } & 6 & \text { Female } \\ & & & \\ \text { Father 2 } & \text { Salesman } & 29 & \text { Male } \\ \text { Mother 2 } & \text { Homemaker } & 32 & \text { Female } \\ \text { Child 2 } & \text { Kindergarten } & 5.5 & \text { Female }\end{array}$

\section{Group B}

\begin{tabular}{llll}
\hline Father 3 & Construction Worker & 50 & Male \\
Mother 3 & Homemaker & 42 & Female \\
Adolescent 3 & Grade 11th & 16 & Female \\
& & 45 & \\
Father 4 & Businessman & 43 & Male \\
Mother 4 & Homemaker & 17 & Female \\
Adolescent 4 & Grade 12th &
\end{tabular}

Table 2. Represents the level of emotion regulation present among the female children and adolescents, high scores mean more Difficulty in Emotion Regulation.

\begin{tabular}{ccccc}
$\begin{array}{l}\text { Group A } \\
\text { Child 1 }\end{array}$ & $\begin{array}{l}\text { Group A } \\
\text { Child 2 }\end{array}$ & \multicolumn{2}{c}{$\begin{array}{l}\text { Group B } \\
\text { Adolescent 3 }\end{array}$} & \multicolumn{2}{c}{$\begin{array}{l}\text { Group B } \\
\text { Adolescent 4 }\end{array}$} \\
\hline 108 & 90 & 68 & 150 \\
\hline 20 & 9 & 11 & 26 \\
\hline 13 & 10 & 11 & 23 \\
\hline 19 & 17 & 12 & 29 \\
\hline 19 & 19 & 9 & 16 \\
\hline 22 & 16 & 18 & 37 \\
\hline 15 & 18 & 6 & 22
\end{tabular}

\section{Figures}




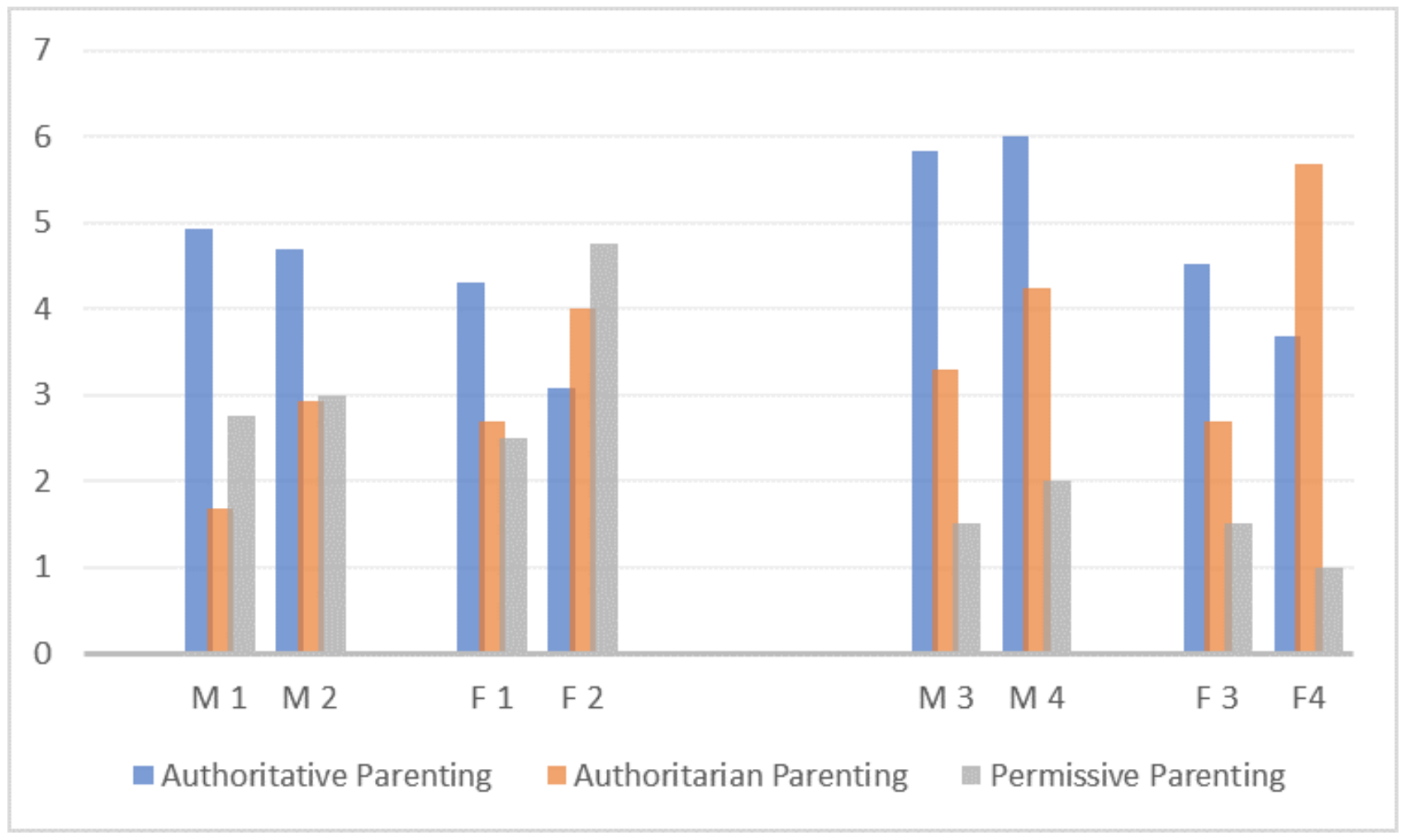

\section{Figure 1}

Mothers and fathers from Group A (M1, F1, M2, F2) and Group B (M3, F3, M4, F4). Fathers (F3, F4), as compared to the mothers $(M 3, M 4)$, are more likely to have a tendency to be authoritarian towards their female offspring $(A=2.69,4, B=$ $2.69,5.69)$. Fathers from both the groups, have showed increasing patterns of authoritarian style of parenting, while those from Group $B$ having a lower degree of permissive behaviour towards their adolescents $(B=1.5,1)$. But have a greater tendency to be permissive when their child is much younger $(A=2.5,4.7 .5)$.

\section{Supplementary Files}

This is a list of supplementary files associated with this preprint. Click to download.

- SupplementaryAdvertisementMaterial.png 